\title{
Shifting the Focus of Green Building Rating Systems: A Structural Engineering Assessment of Existing Systems Including Building Life Cycle Considerations
}

\author{
Dane Miller ${ }^{1}$ and Jeung-Hwan Doh ${ }^{2}$
}

\begin{abstract}
The incorporation of sustainability principles into structural engineering design of buildings has been poorly conducted. Numerous Green Building Ratings Systems (GBRS) exist to attempt to improve this. These systems have focused largely on Operational Energy (OE) efficiencies and management aspects to attain high assessment scores. Previous research has identified this focus to be inconsistent with published data in comparison with the overall Building Life Cycle (BLC) impacts. The consideration of structural elements, through which structural engineers have the greatest ability to influence outcomes, was shown to account for over $20 \%$ of BLC considerations. However these elements only account for approximately $10 \%$ of points achievable under existing GBRS. The advent of Zero Energy Buildings (ZEB) will result in the gap between these values increasing, further highlighting the requirement for the improvement in the focus of existing GBRS if they are to achieve any quantifiable overall improvements to buildings environmental performance. This research builds on the outcomes of previous research and the identification of these discrepancies. The research proposes methods to improve the focus of GBRS in order to bring them into line with the current understanding of total BLC energy consumptions and environmental impacts.
\end{abstract}

Keywords: building life cycle, embodied energy, green building rating system, operational energy.

\section{Introduction}

The construction, operation and maintenance of buildings are estimated to account for approximately 40 - 50\% of all energy usage and anthropogenic GHG emissions globally (Hasegawa 2003, Smith 2005, Asif et al. 2007, Citherlet and Defaux 2007, Wood 2007, Dimoudi and Tompa 2008, Stephan et al. 2011, Dixit et al. 2012, Baek et al. 2013, Langston and Langston 2013, Miller and Doh 2014, Miller et al. 2014). In addition to these, it has been reported that the OE contribution from buildings to total energy consumption in the United States, European Union and the United Kingdom are 40\%, 37\%, and 29\% respectively (Pérez-Lombard et al. 2008, Environmental Protection Agency (EPA) 2009). In states that rely heavily on a service driven economy, for example Hong Kong, this proportion can be as high as $80 \%$ (Chau et al. 2012). The factors contributing to this and requirement for its improvement have been previously extensively discussed (Miller and Doh 2014). Specifically, in Australia, in order to keep pace with growing demand, approximately 30 million tonnes of finished building products are produced each year. Over $56 \%$ of this quantity, by mass, attributed to concrete and a further 6\%, steel (Walker-Morrison et al. 2007). Similar observations are made in other parts of the developed world with for example

\footnotetext{
$1 \quad$ Research Fellow, School of Engineering, Griffith University, Parklands Drive, Southport, Australia. Email: dane.miller@griffith.edu.au

2 Senior Lecturer, School of Engineering, Griffith University, Parklands Drive, Southport, Australia. Tel: +61 75552 9141, Email: j.doh@griffith.edu.au
} 
- the development industry consuming over $40 \%$ of all raw stone, gravel and sand material, $25 \%$ of all raw timber, $40 \%$ of energy and $16 \%$ of water in the United States (Lippiatt 1999, Chong et al. 2009). It is also reported that globally, the production of cement alone causes between 5 and $7 \%$ of $\mathrm{CO}_{2}$ emissions due to the consumption of fossil fuels (Flower and Sanjayan 2007, Oh et al. 2014).

The focus of environmental performance in a given structure is on the OE phase of a BLC compared with embodied energy (EE) (Yeo and Gabbai 2011, Miller and Doh 2014). Significantly, these OE requirements are increasingly negated by the emergence of ZEB. A number of studies are beginning to appear in the development of these ZEB (Crawford 2011, Marszal and Heiselberg 2011, Monahan and Powell 2011, Zuo et al. 2012). If achieved, the contribution of the OE phase would be removed entirely resulting in a major shift in assessing the environmental performance of structures. In concurrence with this shift, GBRS have been developed by the construction industry to attempt to mitigate the environmental impact of the industry. The potential for these GBRS to effectively assess, and promote, sustainable development is well documented with numerous studies identifying their importance (Bilec et al. 2007, Department of the Environment and Water Resources (DEWR) 2007, Deane 2008, Ding 2008, Clark n.d). Conversely, issues with these assessment tools have also been identified (Ding 2008, Dixit et al. 2012). Ding (2008) noted that while there is no doubt these assessment methods contribute to the goal of sustainable development (SD), the current assessment systems have limitations in their effectiveness and usefulness. Ding (2008) concluded that there is a requirement for greater collaborations across the building industry to promote and improve these existing GBRS.

Previous research has identified shortfalls in both the consideration of BLC components when considering environmental performance of structures and the specific requirement for changes in the assessment of GBRS to match the existing state of knowledge (Miller et al. 2014, Miller et al. 2015). The outcome of the assessment conducted by Miller et al. (2014) highlighted the consideration of EE by establishing that Greenstar allocated $7 \%$ of points available to structural design, while BREEAM and LEED allocated 11\% and 8\% of credits respectively to the structural system. This was further extended by Miller et al. (2015) to incorporate the results of an industry survey to establish baseline data for the EE consumption in total BLC by structural systems. Through all factors considered - the mean EE consumption determined was 18.6\% of the BLC energy consumption (Miller et al. 2015). When compared with the consideration of the points available through GBRS presented, the requirement for their improvement is clear.

Previous progress has remained languid in the generation of the identified requirements of universally applicable solutions. This research was conducted to detail a more short-term solution to assist in the adoption of quantifiable environmental improvements for the construction industry. The research proposes adjustments to GBRS to close the existing gap between literature and the existing GBRS mechanisms. This research focused on the selected GBRS due to the popularity of these systems and existence of other relevant research, however, similar approaches would be applicable to all existing GBRS incorporating criteria-based assessment processors. The aim of this manuscript was to present an alternative to the current approach of popular GBRS, promoting their improvement through increased EE considerations in criteria-based assessment methods.

\section{Methods}

Previous research outcomes were utilised for the consideration of both points allocated to structural systems in existing GBRS (Miller et al. 2014), and understanding of the existing literature in this field (Miller et al. 2015). By identifying the disparity between these two factors, improvement was suggested through two potential alternatives: 1) The redistribution 
of points in the existing GBRS and 2) The addition of a new complimentary assessment category. The methodology applied for the approach to each of these potential options was described in detail below.

The methodology adopted for the completion of this research enabled the determination of outcomes consistent with the identified required improvements by Miller et al. (2015). For the GBRS considered, Greenstar allocated $7 \%$ of points available to structural design, while BREEAM and LEED allocated $11 \%$ and $8 \%$ of credits respectively to the structural system through EE (Miller et al. 2014). These were used as the input data for the redistribution of points with appropriate weightings applied to increase the corrected $\mathrm{EE}$ contributions of Greenstar, BREEAM and LEED to be in line with the average value of $18.6 \%$ of the BLC energy consumption determined by Miller et al. (2015).

\section{Redistribution of Points}

Weighting factors were assigned to categories of the GBRS considered based on the outcomes of previous research (Miller et al. 2015). Two methods were identified to adjust the weight of credits. Method 1 involved applying a single factor to all rating criteria that either wholly or partially allocated points to the structural system. Method 2 involved identifying the category with the most points allocated to the structural system. This category could be re-weighted as a whole. This method was proposed due to the reliance on "Materials" (or equivalent) categories in the three GBRS for EE considerations.

Method 1: An example of the process described for Method 1 was presented (Table 1). This details the results of proportionally adjusting the distribution of points based on the outcomes of Miller et al. (2014) to become consistent with the average BLC energy contributions identified by Miller et al. (2015). The factors listed in Table 1 were applied to all relevant marks.

Method 2: An example of the methodology proposed for Method 2 was presented (Table 2). This required identification of the largest contributor to structural points achievable in the GBRS assessed (materials or equivalent). Similarly to Method 1, this aimed to achieve a redistribution of points to be consistent with published literature and previous research findings (Miller et al. 2014, Miller et al. 2015).

\section{Development of a complimentary GBRS category}

A new category was proposed to more appropriately implement additional rating criteria. The addition of a new rating category to assess more specific structural consideration would provide manifold potential benefits. A new category titled here: Construction Energy and Structural System (CESS) would compliment the current GBRS categories for concrete structures. The development of this category was conducted based on extensive previous knowledge and research by the authors including (Miller and Doh 2014, Miller et al. 2014, Miller et al. 2015, Miller et al. 2015). It proposed the inclusion of criteria detailed below for addition as a new category to compliment the GBRS assessed.

\section{Results and Discussion}

Outcomes detailed the potential suitability of these two options as short-term resolutions to the existing identified shortfalls of GBRS (Ding 2008, Dixit et al. 2012). The outcomes of this research calibrate these existing GBRS to be in accordance with the knowledge of the field in relation to equivalent BLC energy consumption contributions. Miller et al (2014) and Miller et al. (2015) identified the discrepancies between these existing OE vs EE energy requirements when compared with the current approach of existing GBRS. After conducting the re-calibration of these GBRS outcomes, the percentage of points allocated to the structural system of a building using Method 1 have been presented in Table 1 . 
Table 1. Re-weighting of points for criteria contributing to EE in the GBRS assessed

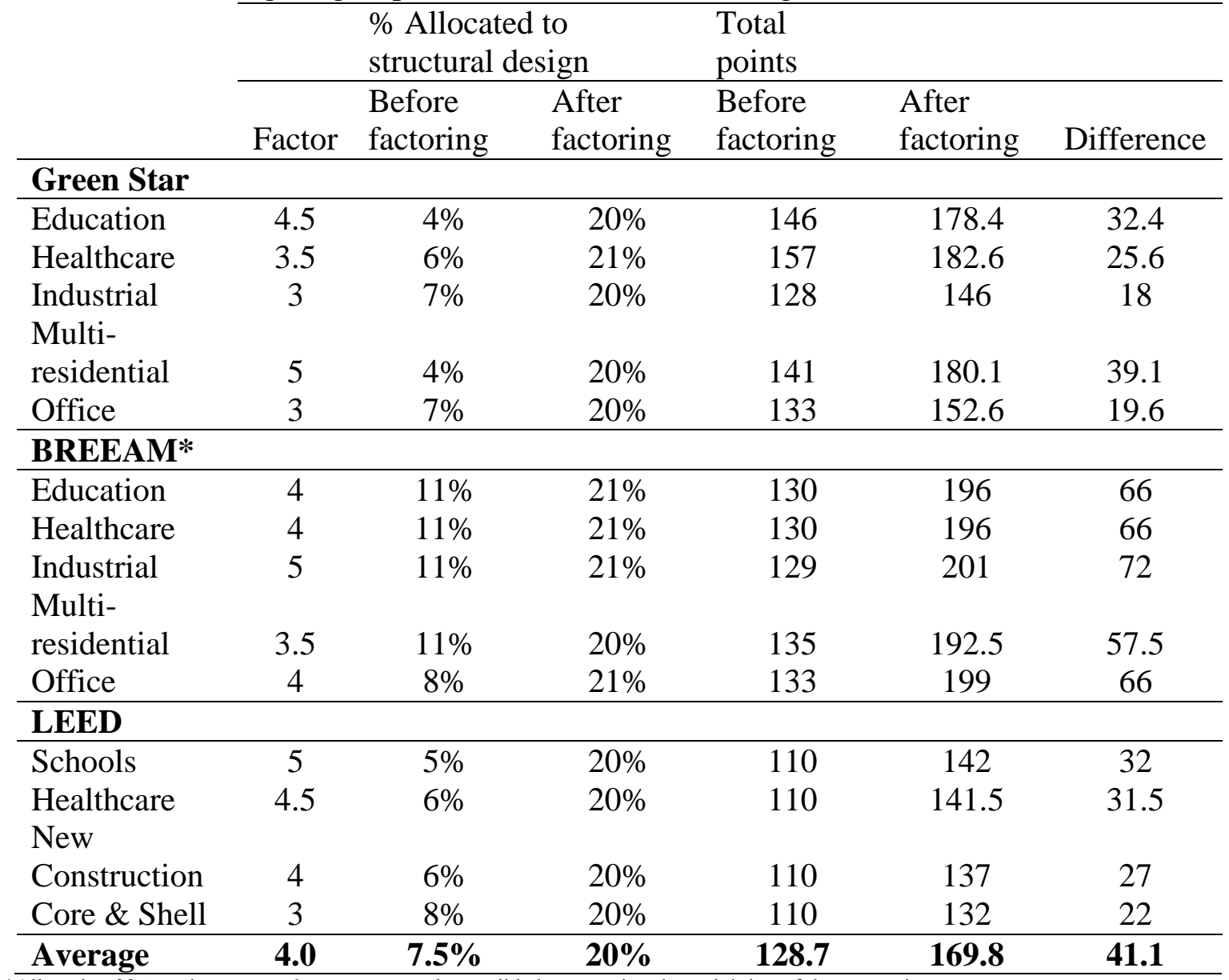

*Allocating $20 \%$ to the structural system was only possible by removing the weighting of the categories.

It was aimed to achieve an overall mark allocation to structural design of approximately 20\% (Miller et al. 2014, Miller et al. 2015). This was the approximate proportion of BLC energy consumption attributed to EE. To achieve this, large weighting factors (ranging from 3 to 5) were required, depending on GBRS and building end-use option. As noted, additional modifications would be required for other GBRS using this methodology.

Similarly, after conducting the re-calibration of these GBRS outcomes, the percentage of points allocated to the structural system of a building and therefore the EE requirements of a structure using Method 2 have been presented in Table 2.

The outcomes of both Method 1 and 2 enabled the outcomes of criteria-based assessment scores to accurately reflect the correct distribution of points in accordance with Miller et al. (2015).

A summary of the CESS category recommended was provided in Table 3. A total of 23 marks were proposed based on the previous research outcomes and knowledge of the existing GBRS. The proposed was in agreement with the suggested requirements for improvement of the mechanisms by (Ding 2008, Dixit et al. 2012, Miller et al. 2015). The weighting of the category was dependent on the building type due to specifics in the existing GBRS. 
Table 2. Re-weighting of points in a single category of the GBRS assessed

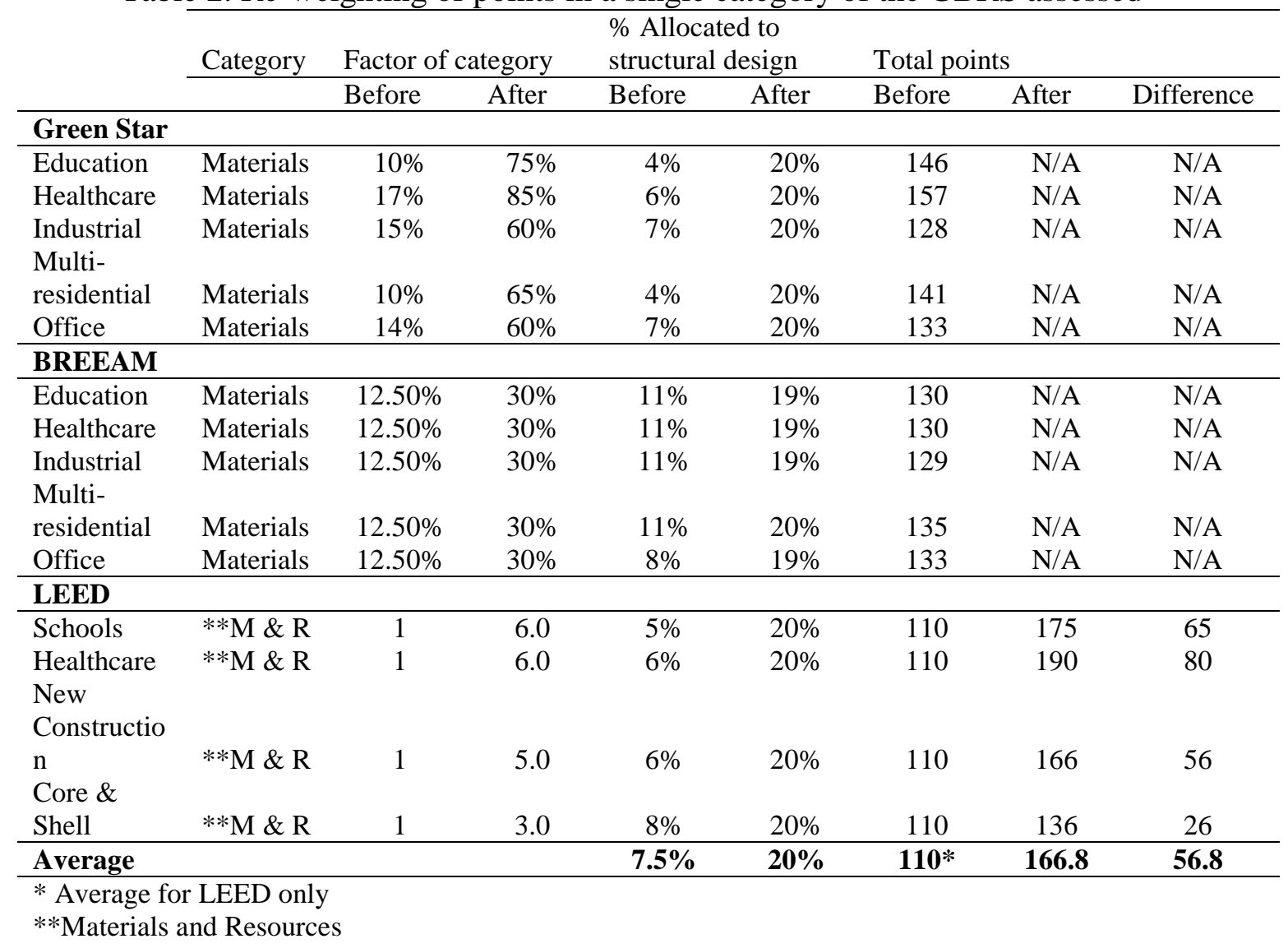

Table 3. Summary of marks in the proposed CESS category

\begin{tabular}{llc}
\hline Category & Subcategory & Points earned \\
\hline Height / Footprint Ratio & & 2 \\
Structural Engineering & Certification & 1 \\
Professional & Involvement in the Project & 1 \\
Structural Waste Reduction & Preliminary Design & 2 \\
Span Efficiency & Detailed Design & 2 \\
& Concrete & 1 \\
Concrete \& Steel Efficiency & Steel & 2 \\
Mineralisation of the Frame & & 2 \\
Life Cycle Design & Planning & 3 \\
Advanced Design Technologies & & 2 \\
Total & Level of Recycling & 2 \\
\hline
\end{tabular}

Table 4 shows how the CESS category integrates with the existing Greenstar GBRS as an example. The weight of this category was $14 \%$ or $15 \%$, dependent on building end-use type. It was determined that an allocation of approximately $20 \%$ of points to the structural system was desired to be consistent with previously published literature (Miller et al. 2014, Miller et al. 2015). 
Table 4. Recommended weighting of the CESS category for the GBRS considered

\begin{tabular}{|c|c|c|c|c|c|c|c|c|c|c|}
\hline \multirow[t]{3}{*}{ Category } & \multicolumn{10}{|c|}{ Weight (\%) } \\
\hline & \multicolumn{2}{|c|}{ Education } & \multicolumn{2}{|c|}{ Healthcare } & \multicolumn{2}{|c|}{ Industrial } & \multicolumn{2}{|c|}{$\begin{array}{l}\text { Multi- } \\
\text { residential }\end{array}$} & \multicolumn{2}{|c|}{ Office } \\
\hline & O* & $\mathrm{P} * *$ & O* & $\mathrm{P}^{* *}$ & $\mathrm{O}^{*}$ & $\mathrm{P}^{* *}$ & O* & $\mathrm{P} * *$ & O* & $\mathrm{P} * *$ \\
\hline \multicolumn{11}{|l|}{ Managemen } \\
\hline $\mathrm{t}$ & $10 \%$ & $8 \%$ & $9 \%$ & $7 \%$ & $10 \%$ & $8 \%$ & $8 \%$ & $6 \%$ & $9 \%$ & $7 \%$ \\
\hline IEQ & $20 \%$ & $16 \%$ & $20 \%$ & $16 \%$ & $17 \%$ & $14 \%$ & $20 \%$ & $16 \%$ & $20 \%$ & $16 \%$ \\
\hline Energy & $25 \%$ & $25 \%$ & $24 \%$ & $24 \%$ & $24 \%$ & $24 \%$ & $25 \%$ & $25 \%$ & $25 \%$ & $25 \%$ \\
\hline Transport & $10 \%$ & $8 \%$ & $7 \%$ & $6 \%$ & $8 \%$ & $7 \%$ & $10 \%$ & $8 \%$ & $8 \%$ & $7 \%$ \\
\hline Water & $15 \%$ & $12 \%$ & $12 \%$ & $10 \%$ & $9 \%$ & $7 \%$ & $15 \%$ & $12 \%$ & $12 \%$ & $10 \%$ \\
\hline Materials & $10 \%$ & $8 \%$ & $17 \%$ & $14 \%$ & $15 \%$ & $12 \%$ & $10 \%$ & $8 \%$ & $14 \%$ & $11 \%$ \\
\hline Land Use \& & & & & & & & & & & \\
\hline Ecology & $5 \%$ & $4 \%$ & $8 \%$ & $6 \%$ & $8 \%$ & $7 \%$ & $7 \%$ & $6 \%$ & $6 \%$ & $5 \%$ \\
\hline Emissions & $5 \%$ & $4 \%$ & $3 \%$ & $2 \%$ & $9 \%$ & $7 \%$ & $5 \%$ & $4 \%$ & $6 \%$ & $5 \%$ \\
\hline CESS & $0 \%$ & $15 \%$ & $0 \%$ & $15 \%$ & $0 \%$ & $14 \%$ & $0 \%$ & $15 \%$ & $0 \%$ & $14 \%$ \\
\hline $\begin{array}{l}\text { Weight of } \\
\text { structural } \\
\text { contributio } \\
\text { n }\end{array}$ & $4 \%$ & $19 \%$ & $7 \%$ & $20 \%$ & $6 \%$ & $20 \%$ & $4 \%$ & $18 \%$ & $7 \%$ & $20 \%$ \\
\hline
\end{tabular}

Both the "original” and "proposed" results were presented in Table 4, for comparison of the current approach against that proposed by this research. Variations in existing weightings using the CESS category were minor while concurrently enabling the more appropriate distribution of weighting to be consistent with known BLC energy consumptions (Miller et al. 2015). It was also important to consider these outcomes were based on the current discrepancies observed, ignoring the influence the advent of ZEBs will have on these results by removing the OE considerations of structures entirely (Crawford 2011, Marszal and Heiselberg 2011, Monahan and Powell 2011, Zuo et al. 2012).

\section{Conclusions}

Reconsidering existing weighting of credits was considered a less effective approach to allow GBRS to consider proportions of OE and EE appropriately. Concerns were raised for both methods proposed, including the potential truncation errors and the reliance of major adjustments. These modifications could compromise the overall intent of the scoring systems. In addition, it was stated that all credits related to the structural system were earned through material selection. Efficient design, and therefore efficient use of materials, was not awarded or considered. The addition of the CESS category involving EE of the structural system was considered a more comprehensive approach.

The concern with rescaling the GBRS without adding additional rating criteria was the large weighting factors required for $\mathrm{EE}$ and $\mathrm{OE}$ to be represented appropriately (Method 1 and Method 2). The proposed CESS category requires minimum downscaling of the other categories. No more than four percentage points were removed from any category. Given the significance of the 'Energy' category (or equivalent), this weighting was maintained.

Further validation of the proposed approach would be recommended using case studies and examples for refinement of the distribution of points proposed using the developed CESS category. While the existing GBRS play an important role in the progress of the 
construction industry to matters of environmental performance, these outcomes have further highlighted the potential for their improvement.

\section{Acknowledgement}

This research would not have been possible without incorporating the outcomes of previous research. The authors of these previous publications are thanked for their input and contribution. In addition, Mr. Niek van Oers provided input to these research outcomes through previous research with the authors. He is thanked for his contribution.

\section{References}

Asif, M., T. Muneer and R. Kelley 2007. Life Cycle Assessment: A Case study of a dwelling home in Scotland. Building and Environment 42: 1391-1394.

Baek, C., S.-H. Park, M. Suzuki and S.-H. Lee 2013. Life cycle carbon dioxide assessment tool for buildings in the schematic design phase. Energy and Buildings 61: 275-287.

Bilec, M., R. Ries and H.S. Matthews 2007. Sustainable Development and Green Design Who Is Leading the Green Initiative? Joural of Professional Issues in Engineering Education and Practice: 265-269.

Chau, C.K., W.K. Hui, W.Y. Ng and G. Powell 2012. Assessment of CO2 emissions reduction in high-rise concrete office buildings using different material use options. Resources, Conservation and Recycling 61: 22-34.

Chong, W.K., S. Kumar, C.T. Haas, S.M.A. Beheiry, L. Coplen and M. Oey 2009. Understanding and Interpreting Baseline Perceptions of Sustainability in Construction among Civil Engineers in the United States. Journal of Management in Engineering 25(3): 143-154.

Citherlet, S. and T. Defaux 2007. Energy and environmental comparison of three variants of a family house during its whole life span. Building and Environment 42(2): 591-598.

Clark, D. (n.d). Incentives for Sustainable Buildings in Australia - A Designer's Perspective, Sinclair Knight Merz.

Crawford, R.H. 2011. Towards a comprehensive approach to zero-emissions housing. Architectural Science Review 54(4): 277-284.

Deane, M. 2008. The builder's role in delivering sustainable tall buildings. The Structural Design of Tall and Special Buildings 17(5): 869-880.

Department of the Environment and Water Resources (DEWR) (2007). ESD Design Guide: Office and Public Buildings 3rd Edition. Canberra, Commonwealth of Australia: 74.

Dimoudi, A. and C. Tompa 2008. Energy and environmental indicators related to construction of office buildings. Resources, Conservation and Recycling 53(1-2): 86-95.

Ding, G.K. 2008. Sustainable construction--the role of environmental assessment tools. $J$ Environ Manage 86(3): 451-464.

Dixit, M.K., J.L. Fernández-Solís, S. Lavy and C.H. Culp 2012. Need for an embodied energy measurement protocol for buildings: A review paper. Renewable and Sustainable Energy Reviews 16(6): 3730-3743.

Environmental Protection Agency (EPA) (2009). Buildings and their impact on the Environment: A Statistical Summary. Washington, Environmental Protection Agency.

Flower, D.J.M. and J.G. Sanjayan 2007. Green house gas emissions due to concrete manufacture. The International Journal of Life Cycle Assessment 12(5): 282-288.

Hasegawa, T. (2003). Environmentally Sustainable Buildings - Challenges and Polocies. Frane, (OECD) Organisation for Economic Co-Operation and Development: 194.

Langston, Y.L. and C.A. Langston 2013. Reliability of building embodied energy modelling: an analysis of 30 Melbourne case studies. Construction Management and Economics 26: 147-160. 
Lippiatt, B.C. 1999. Selecting Cost Effective Green Building Products: BEES Approach. Journal of Construction Engineering and Management 125: 448-455.

Marszal, A.J. and P. Heiselberg 2011. Life cycle cost analysis of a multi-storey residential Net Zero Energy Building in Denmark. Energy 36(9): 5600-5609.

Miller, D. and J.-H. Doh 2014. Incorporating sustainable development principles into building design: a review from a structural perspective including case study. The Structural Design of Tall and Special Buildings.

Miller, D., J.-H. Doh, M.M. Lima and N.v. Oers (2014). Embodied Energy Assessment of the Structural System in Concrete Buildings: A Case Study on 7 South East Queensland Structures. 23rd Australasian Conference on the Mechanics of Structures and Materials ACMSM23. S. T. Smith. Byron Bay.

Miller, D., J.-H. Doh and M. Mulvey 2015. Concrete slab comparison and embodied energy optimisation for alternate design and construction techniques. Construction and Building Materials 80: 329-338.

Miller, D., J.-H. Doh, K. Panuwatwanich and N. van Oers 2015. The contribution of structural design to green building rating systems: An industry perspective and comparison of life cycle energy considerations. Sustainable Cities and Society 16: 3948.

Monahan, J. and J.C. Powell 2011. A comparison of the energy and carbon implications of new systems of energy provision in new build housing in the UK. Energy Policy 39(1): 290-298.

Oh, D.-Y., T. Noguchi, R. Kitagaki and W.-J. Park 2014. CO2 emission reduction by reuse of building material waste in the Japanese cement industry. Renewable and Sustainable Energy Reviews 38: 796-810.

Pérez-Lombard, L., J. Ortiz and C. Pout 2008. A review on buildings energy consumption information. Energy and Buildings 40(3): 394-398.

Smith, P.F. 2005. Architecture in a Climate of Change. Oxford, Architectural Press.

Stephan, A., R.H. Crawford and K.d. Myttenaere 2011. Towards a more holistic approach to reducing the energ demand of dwellings. Procedia Engineering 21: 1033-1041.

Walker-Morrison, A., T. Grant and S. McAlister 2007. Strategies and Resources for Material Selection. Environment Design Guide PRO 8.

Wood, A. 2007. Sustainability: A New High-Rise Vernacular? The Structural Design of Tall and Special Buildings 16: 401-410.

Yeo, D. and R.D. Gabbai 2011. Sustainable design of reinforced concrete structures through embodied energy optimization. Energy and Buildings 43(2011): 2028-2033.

Zuo, J., B. Read, S. Pullen and Q. Shi 2012. Achieving carbon neutrality in commercial building developments - Perceptions of the construction industry. Habitat International 36(2): 278-286. 